\title{
The Prevalence of Wheat and Spelt Sensitivity in a Randomly Selected Australian Population
}

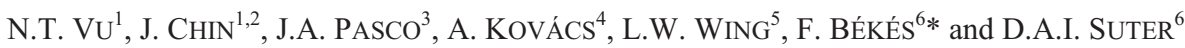 \\ ${ }^{1}$ Faculty of Agriculture and Environment, University of Sydney, Eveleigh, NSW 2015 Australia \\ ${ }^{2}$ Xion Biotechnology, Rhodes, NSW 2138, Australia \\ ${ }^{3}$ School of Medicine, Deakin University, Geelong, VIC 3220, Australia \\ ${ }^{4}$ Agricultural Institute Centre for Agricultural Research of HAS, Martonvásár, H-2462, Hungary \\ ${ }^{5}$ Bondi Junction, NSW 2022, Australia \\ ${ }^{6}$ George Weston Foods P/L, North Ryde, NSW 2113, Australia
}

(Received 20 December 2013; Accepted 14 April 2014)

To determine the prevalence of wheat sensitivity in a randomly selected Australian population, a study was carried out on sera samples of the Geelong Osteoporosis Study (GOS) age-stratified cohorts of men and women who were randomly selected from electoral rolls for the Barwon Statistical Division $(n=1145)$. The human sera were analysed by ELISA-based method using the ImmunoCAP 100 instrument (Phadia, Sweden). IgE from human sera were bound to the wheat (f4) and milk (f2) allergens that have been previously coated on the ImmunoCAPs. The number of IgE wheat and milk RAST positive individuals was determined. In order to relate the increased IgE immuno-reactivity to allergen symptoms, a questionnaire was established and sent to the blood donors and 974 individuals responded. Of these $(n=974) 147$ individuals (15.1\%) reported symptoms caused by wheat consumption, 179 $(15.6 \%)$ and $112(9.8 \%)$ sera showed RAST positive results ( $\operatorname{IgE}>60$ response units) in wheat and milk RAST tests, respectively. However, only $2.5 \%$ of those participants with symptoms related to wheat had positive $\operatorname{IgE}$ values indicating that the relationship is complex: a large proportion (12.7\%) of the investigated population might suffer from other wheat related disorders (i.e. not IgE mediated), such as celiac disease, non-celiac reaction to gluten, reaction to fructans for those with irritable bowel syndrome as well as other factors. For the $13.2 \%$ who showed raised IgE antibody levels without symptoms we postulate that these individuals have latent wheat sensitivity with the potential of developing symptoms sooner or later.

A comparative study to investigate the immune reactivity of human IgE against wheat and spelt antigens was carried out using the sera of 73 patients found to be RAST positive for wheat. Of these $63 \%(n=50)$ showed a higher IgE immune reactivity against wheat, while $30 \%(n=24)$ showed higher IgE response against spelt antigens, the remaining $7 \%$ have indifferent responses against both antigens. Since the provided Phadia wheat and spelt antigens used in this study originated from Europe, Australian wheat and spelt varieties were also used to prepare antigens in order to investigate the response of Australian sera to local wheats. It was found that the immune reactivity of $\operatorname{IgE}$ wheat positive sera from a normal Australian population is lower for spelts compared to wheats regardless of their origin but much lower against an Australian spelt containing a mutation in its expansin gene. A clinical feeding trial would be

* Corresponding author; E-mail: firinc47@gmail.com; Phone: +61 298754029 
necessary to confirm if this difference in immune reactivity between spelt and wheat is consistent with a difference in allergenicity.

Keywords: wheat related health disorders, prevalence of wheat sensitivity, IgE RAST test, expansin

\section{Introduction}

There remains uncertainty regarding the prevalence of food allergy, particularly to fruits, vegetables, nuts, and other edible plants. Although diagnostic studies have objectively verified allergic reactions caused by ingestion of plant food, the extent of the problem on the population level remains unclear for patients and their families, schools, the catering industry, food producers and retailers, health professionals, and policy makers (Zuidmeer et al. 2008).

Consumption of "gluten"-containing food causes a significant disease for a minority group of people who consume foods derived from wheat, rye, barley and oats. Commercial activity related to "gluten toxicity" and "wheat allergy" is largely focused upon "gluten-free" food. The fact is, however, that in several types of diseases related to the consumption of "gluten"-containing cereals, the trigger compounds are not components of the

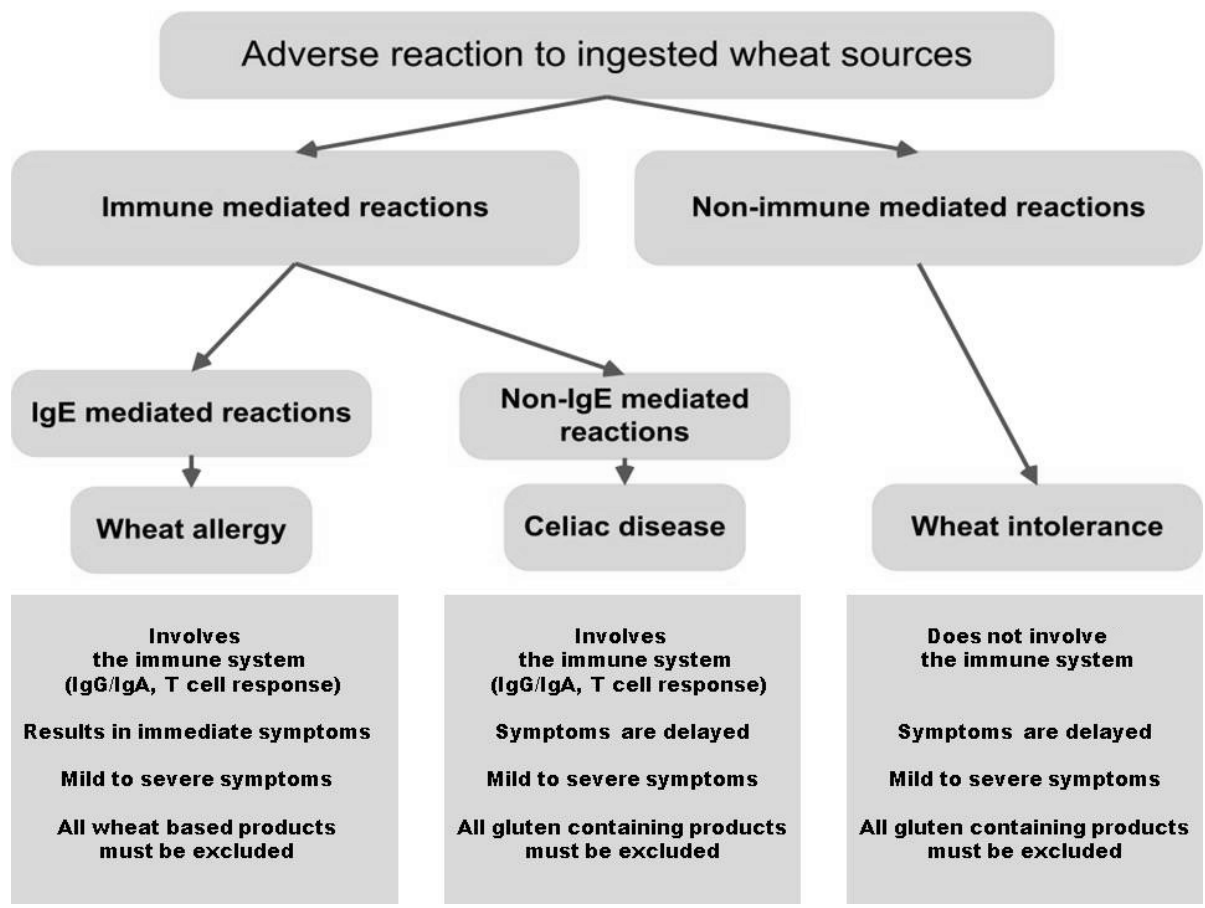

Figure 1. Spectrum of gluten related disorders (based on Sapone et al. 2012) 
gluten. There is a lack of related knowledge about the causes of different symptoms or diseases and about the terms "gluten", "prolamins", "gliadin", "glutenin" not only in the minds of the consumer but also in medical practice (Islam et al. 2011).

The spectrum of "gluten"-related disorders can be divided into three main groups: autoimmune, allergic and not autoimmune allergic disorders (Sapone et al. 2012) (Fig. 1). Two of these disorder types, the autoimmune and the allergic disorders are relatively well described, however, further studies are needed to reveal mechanisms related to the diverse symptoms of allergic reactions. The autoimmune disorders include celiac disease (Anderson and Wieser 2006) gluten athaxia and dermatitis herpetiformis (Laurière et al. 2006). The allergic reactions involve respiratory allergy (Amano et al. 1998), food allergy (Mills et al. 2004), wheat-dependent exercise induced anaphylaxis (Armentia et al. 1990) and contact urticaria. Symptoms of celiac disease are triggered by an abnormal response of auto-antibodies, such as antibodies to tissue-transglutaminase, or antibodies against proline- and glutamine-rich wheat gluten proteins or their barley and rye homologs (Green and Cellier 2007). Celiac disease shows strong association with HLA-DQ alleles and carriage of certain HLA-DQ molecules is the most important genetic factor to develop detrimental symptoms (Sollid et al. 2012). HLA-DQ heterodimers function as surface type receptor proteins bound to the surface of the antigen presenting cells. The presence of HLA-DQ molecules such as DQ 2.5, DQ 8, DQ 2.2 is known as a clear marker for developing autoimmune symptoms, with modifying effects coming from genetic and environmental factors (Anderson et al. 2000). The different serotypes recognize different peptides. A set of criteria can be defined for the structure of an active CD epitope: a) the size of nine amino acids, $b$ ) the presence of a tissue transglutaminase 2 (tTG) enzyme binding site, c) surrounded by amino acids with defined charge and hydrophobicity (Sollid et al. 2012). Patients suffering from celiac disease produce a range of autoimmune responses to several alpha-gliadin, LMW glutenin and gamma-gliadin peptides in the consumed wheat products.

The development of wheat allergies is mediated more directly by the recognition of allergens by specific IgE epitopes bound to mast cells (Catassi and Fasano 2008). Depending on the route of the wheat allergen exposure, symptoms can be divided into symptoms of classic food-allergy; wheat-dependent exercise-induced anaphylaxis (WDEAI); occupational asthma and urticaria (Sapone et al. 2012). Classic food allergy symptoms may affect to the skin, gastrointestinal or respiratory tract. While atopic dermatitis is mainly characteristic on children, WDEIA or urticaria were mostly identified in adults. Bakers' asthma, one of the most prevalent respiratory allergies, is a significant symptom among adults working with wheat flour. In wheat allergy, allergen presenting B-cells and T-cells has the same level of impact and, similar to other food allergies, allergic reactions are the result of special cross-links between specific immunoglobulin $E$ and short peptides rich in glutamine and proline that result from the breakdown of wheat seed proteins by endogenous proteases (Sapone et al. 2012). This interaction stimulates basophils and mast cells to release chemical mediators, such as histamines resulting in different categories of inflammatory reactions. The allergenic regions of protein recognized by the binding sites of IgE molecules are called IgE-binding epitopes. These epitopes can be classified into two cate- 
gories, conformational and linear epitopes and both types are involved in the development of allergic reactions (Akagawa et al. 2007).

The general public in most Western countries is now aware of cereal products that are "high GI" and contain "allergenic" gluten from frequent articles in the media as well as a number of popular books (Braly and Hogganm 2002; Ford 2008; Wangen 2009; Davis 2011), promoting gluten-free diets, many without drawing attention to the importance of appropriate diagnosis or defining what gluten "intolerance" an individual may have. Such adverse publicity poses a significant threat to the grain industry.

There is a considerable variation in the levels of wheat allergy reported in the literature. In the past decade the prevalence of sensitivity to wheat among children and adult patients has been reported to have increased to levels of approximately $15 \%-20 \%$ of the human population, presenting a major health problem in industrial countries (Hischenhuber et al. 2006). Celiac disease primarily affects the Caucasian population of countries where wheat, rye, and/or barley are important nutrients (Corazza and Gasbarrini 1995). Gluten sensitive disease is uncommon in Africa, as well as only rare cases were identified from Eastern and Southern Asia. About 15-20 years ago, the reported cumulative incidence rate of celiac disease in Europe was widely different ranging between 1:400-1:12800 births; however, with the development of diagnostic tools the reported prevalence rates have reached the 1:100-1:300 in the European countries (Greco et al. 1992; Anderson and Wieser 2006).

Clinical symptoms of wheat allergy are often similar to those of celiac disease (urticaria, atopic dermatitis, nausea, vomiting, diarrhoea, rhinitis, anaphylaxis, etc.). However, their pathogenic mechanisms are different, therefore their differentiation, diagnosis and treatment can be challenging. The diagnosis of food allergy to wheat is often not well predicted by the increased level of serum specific $\mathrm{IgE}$ caused by wheat consumption (Ortolani and Pastorello 2006). The true prevalence of food allergy is difficult to establish; however, research indicates the incidence is increasing in the population. The prevalence of wheat sensitization in a population based on specific IgE investigated in several European countries indicated slightly higher perception of allergic reaction than that of sensitization assessed by skin prick test (Rona et al. 2007).

The growing number of wheat related food disorders draws attention to this serious health concern. In addition to the obvious detrimental effects of health and daily diet, there are potentially long-term medical, psychological, and social effects. Correctly diagnosing wheat and gluten related disorders is often challenging, especially given the limitations of current diagnostic testing. However, it is important to prevent children from unnecessary invasive treatments and potentially unhealthy dietary restrictions. Therefore, research is needed to determine the precise prevalence of different wheat and gluten related disorders, to discover more accurate and less invasive procedures for identification of the mechanisms that lead to adverse reactions against wheat and related cereals and find suitable source materials with low or no allergenic effects.

The two aims of this study were to determine of the prevalence of wheat sensitization in a large randomly selected Australian population for specific IgE and to compare the immune reactivity of wheat and a novel spelt line based on its soluble protein composition. 


\title{
Materials and Methods
}

\section{Sera sample selection}

\begin{abstract}
A large set of blood samples from randomly selected individuals $(n=1145)$ was obtained from the Geelong Osteoporosis Study (GOS), Geelong, Victoria, Australia. Serum samples of the GOS age-stratified cohorts of men $(n=1540$ in 2001-2006) and women $(n=$ 1494 in 1994-1997 and $n=221$ in 2006-2008) that were randomly selected from the electoral rolls of the Barwon Statistical Division. In 2009-2010, participants were invited to participate in this sub-study (Pasco et al. 2012). From a group of 2075 potential participants, 1145 provided blood samples for the analyses of IgE against wheat and milk antigens. All participants provided written consent and the study was approved by the Barwon Health Human Research Ethics Committee, Australia.
\end{abstract}

\section{Determination of IgE levels by Phadia ImmunoCAP 100}

The human sera were analysed by ELISA-based method using the ImmunoCAP 100 instrument (Phadia, Sweden). IgE from human sera were bound to the wheat (f4) and milk (f2) allergens that have been previously coated on the ImmunoCAPs. Bound IgE were captured by the anti-IgE conjugate and the conjugate enzyme reacts with the flourogenic substrate to form a fluorescent product (Johansson 2004). Reactivity was detected as response units and IgE concentration $(\mathrm{kU} / \mathrm{L})$ was calculated from the standard curve.

A subset of individuals $(n=73)$ with positive reactivity against wheat (f4) from the GOS cohort (Pasco et al. 2012) were selected and further analysed for IgE against spelt antigen (f124) using the ImmunoCAP 100 (Phadia, Sweden). Six individuals with low sensitivity to wheat (3 low in milk, 3 high in milk) were also selected as negative controls.

A similar assay was also developed (adapting the method of Erwin et al. 2005) in order to compare the reaction of the above subset of 73 individuals, having raised $\mathrm{IgE}$ to wheat, against in-house prepared antigens from Australian wheat and spelt (GWF spelt). The analysis of the Australian derived antigens was optimized by coupling the soluble antigens with streptavidin beads and assayed using the Phadia ImmunoCAP 100 machine.

\section{Coupling of wheat and spelt antigens to streptavidin caps}

Grains of wheat cultivar Kukri and a spelt line (GWF spelt) with unusual soluble protein composition ( $\mathrm{Vu} 2014$ ) were milled and soluble proteins were extracted according to the modified method of Osborne protocol (Scholz et al. 2000). The concentrations of the water soluble proteins were determined by the bicinchoninic acid (BCA) protein assay kit (Pierce). Purified antigens were biotinylated according to the Pierce EZ-Link $\AA$ Biotinylation Kit (Thermo Fisher). The streptavidin caps have been pre-washed and the biotinylated antigens were added.

Survey for symptoms associated with food consumption

Food allergy questionnaires were provided by Barwon Health (Victoria, Australia) to the GOS participants and statistical analyses were conducted to establish relationships be- 
tween individuals with clinical symptoms and immune-responses. The population has been divided into four subgroups: a) real positives where positive immune-responses corresponded with clinical symptoms, b) real negatives with no immune-response and no reported clinical symptoms, c) false positives where immune-response has been detected without clinical symptoms and d) false negatives no immune responses were found while clinical symptoms have been reported.

\section{Results}

\section{IgE responses against wheat (f4) and milk (f2) in the GOS cohort}

Based on the IgE cut-off of 60 response unit (equivalent to $0.1 \mathrm{kU} / \mathrm{L}$ ) (Phadia, Sweden), $14.1 \%$ (162 individuals) and 8.4\% (96 individuals) of the population showed raised IgE antibody levels against wheat and milk, respectively (Table 1). From the $14.1 \%$ raised IgE levels against wheat antigen, $2.6 \%(n=30)$ are considered to be wheat allergic class 1 (IgE: $0.35-0.70 \mathrm{kU} / \mathrm{L}), 2.3 \%(n=27)$ in class $2(\operatorname{IgE}: 0.71-3.50 \mathrm{kU} / \mathrm{L})$ and $1.0 \%(n=11)$ in class $3(\mathrm{IgE}: 3.51-17.50 \mathrm{kU} / \mathrm{L})$. The remaining $8.2 \%(n=94)$ with $\operatorname{IgE}$ between $0.10-0.35 \mathrm{kU} / \mathrm{L}$ may be considered as low level and have the possibility of developing sensitisation to wheat later in life.

Table 1. IgE responses against wheat (f4) and milk (f2) in the GOS cohort

\begin{tabular}{|c|c|c|c|c|c|}
\hline \multicolumn{3}{|c|}{ Wheat (f4) } & \multicolumn{3}{|c|}{ Milk (f2) } \\
\hline \multirow{2}{*}{$\begin{array}{l}\mathbf{I g E}>\mathbf{0 . 1} \mathbf{~ k U / L ~ ( 6 0 ~ R U ) ~} \\
\text { Allergic Class }(\mathrm{kU} / \mathrm{L}) \\
\end{array}$} & \multicolumn{2}{|c|}{$n=162(14.1 \%)$} & \multirow{2}{*}{$\begin{array}{l}\mathbf{I g E}>\mathbf{0 . 1} \mathbf{~ k U / L ~ ( 6 0 ~ R U ) ~} \\
\text { Allergic Class }(\mathrm{kU} / \mathrm{L})\end{array}$} & \multicolumn{2}{|c|}{$n=96(8.4 \%)$} \\
\hline & No. & $\%$ & & No. & $\%$ \\
\hline Class $0(0.10-0.35)$ & 94 & 8.2 & Class $0(0.10-0.35)$ & 69 & 6.0 \\
\hline Class $1(0.35-0.70)$ & 30 & 2.6 & Class $1(0.35-0.70)$ & 10 & 0.9 \\
\hline Class $2(0.71-3.50)$ & 27 & 2.3 & Class $2(0.71-3.50)$ & 16 & 1.4 \\
\hline Class $3(3.50-17.50)$ & 11 & 1.0 & Class $3(3.50-17.50)$ & 1 & 0.1 \\
\hline IgE $<0.1 \mathrm{kU} / \mathrm{L}(60 \mathrm{RU})$ & \multicolumn{2}{|c|}{$n=983(85.9 \%)$} & IgE $<0.1 \mathrm{kU} / \mathrm{L}(60 \mathrm{RU})$ & \multicolumn{2}{|c|}{$n=1049(91.6 \%)$} \\
\hline
\end{tabular}

For milk we found $0.9 \%(n=10)$ are class $1,1.4 \%(n=16)$ are class $2(\operatorname{IgE}: 0.71-3.50$ $\mathrm{kU} / \mathrm{L})$ and $0.1 \%(n=1)$ are class 3 ; while $6.0 \%(n=69)$ have IgE levels between $0.10-0.35$ $\mathrm{kU} / \mathrm{L}$. The prevalence of milk allergy based on serum IgE assessment ranges from $2 \%$ to 9\% in European countries (Rona et al. 2007). In Australia, based on the GOS cohort, we found that $2.4 \%$ of the randomly selected population are sensitized to milk (IgE cut-off $0.35 \mathrm{kU} / \mathrm{L})$, while the remaining $6.0 \%$ with raised $\operatorname{IgE}(>0.10 \mathrm{kU} / \mathrm{L})$ have the possibility of developing sensitization later on in life.

\section{Prevalence of wheat sensitivity in a randomly selected Australian population}

In order to relate the increased IgE immune-reactivity to allergen symptoms, a set of questionnaires was established and sent to the blood donors; 974 individuals responded. Based on the questionnaires for conditions associated with food types and the intensity ranging 
from none to strong severity, $15.3 \%(n=149)$ reported symptoms caused by wheat consumption and $11.7 \%(n=114)$ experienced symptoms with milk (Table 2$)$.

Results from ImmunoCAP $100 \mathrm{IgE}$ and questionnaires were superimposed to correlate the prevalence of raised IgE against wheat antigen and symptoms associated with consumption of wheat. From the 974 responses, $15.3 \%(n=149)$ have raised $\operatorname{IgE}>0.10 \mathrm{kU} / \mathrm{L}$, while $84.7 \%(n=825)$ have $\operatorname{IgE}<0.10 \mathrm{kU} / \mathrm{L}$. From the $15.3 \%$ of raised $\mathrm{IgE}$ individuals, only $2.5 \%(n=24)$ have reported symptoms, while $12.8 \%(n=125)$ have no symptoms associated with consumption of wheat-based products. On the other hand, $12.9 \%(n=126)$ of the low $\operatorname{IgE}$ levels $(\mathrm{IgE}<0.10 \mathrm{kU} / \mathrm{L})$ reported symptoms associated with ingestion of wheat, while $71.8 \%(n=699)$ have no reactions.

Table 2. Prevalence of wheat and milk sensitivity in a randomly selected Australian population: Raised IgE against wheat and milk antigen and reported symptoms associated with consumption of wheat and milk

\begin{tabular}{|c|c|c|c|c|}
\hline & & \multirow[b]{2}{*}{$N(\%)$} & \multicolumn{2}{|c|}{ Symptoms } \\
\hline & & & $\begin{array}{c}\text { Yes } \\
N(\%)\end{array}$ & $\begin{array}{c}\text { No } \\
N(\%)\end{array}$ \\
\hline \multirow[t]{3}{*}{ Wheat } & $n$ & $976(100.00)$ & $149(15.27)$ & $825(84.53)$ \\
\hline & $\operatorname{IgE}>60$ & $149(15.27)$ & $24(2.46)$ & $125(12.81)$ \\
\hline & $\operatorname{IgE} \leq 60$ & $827(84.73)$ & $126(12.91)$ & $699(71.62)$ \\
\hline \multirow[t]{3}{*}{ Milk } & $n$ & $974(100.00)$ & $114(11.70)$ & $860(88.30)$ \\
\hline & $\operatorname{IgE}>60$ & $164(16.40)$ & $14(1.44)$ & $122(12.53)$ \\
\hline & $\operatorname{IgE} \leq 60$ & $824(84.60)$ & $86(8.83)$ & $738(75.77)$ \\
\hline
\end{tabular}

\section{IgE responses against wheat (f4) and spelt (f124)}

Individuals $(n=73)$ with cut off $\operatorname{IgE}>60$ response unit $(\mathrm{RU})$ (equivalent $0.10 \mathrm{kU} / \mathrm{L}$ ) against wheat antigen (f4) were further analysed for IgE against spelt antigen (f124) and 6 individuals with $\operatorname{IgE}<60 \mathrm{RU}$ were selected as negative controls.

Each of the 73 sera in this selected group showed higher immune-response to wheat than the cut off value of 60 , while only 64 individuals have $\operatorname{IgE}>60$ RU against spelt antigen (Fig. 2). 49\% $(n=39)$ of the individuals sera showed greater IgE response against wheat than spelt, where $39 \%(n=31)$ of these individuals sera have IgE $>60$ RU against spelt. In contrast, $29 \%(n=23)$ are more responsive to spelt than wheat; and $22 \%(n=17$; where 6 are negative controls and 11 sera have $\operatorname{IgE}>60 \mathrm{RU})$ have similar response against both antigens.

\section{Immunoreactivity of GWF spelt}

Since the commercial wheat and spelt antigens used in the Phadia assay system originated from Europe, a commercial bread wheat cultivar, Kukri and a spelt line (GWF spelt) with unusual soluble protein composition ( Vu 2014) have been selected to examine the differences from an Australian consumer perspective and from the point of view of soluble protein composition. The comparison between commercial antigens and coupled soluble proteins from the Australian wheat and GWF spelt showed good correlations where $\mathrm{r}^{2}=0.92$ 


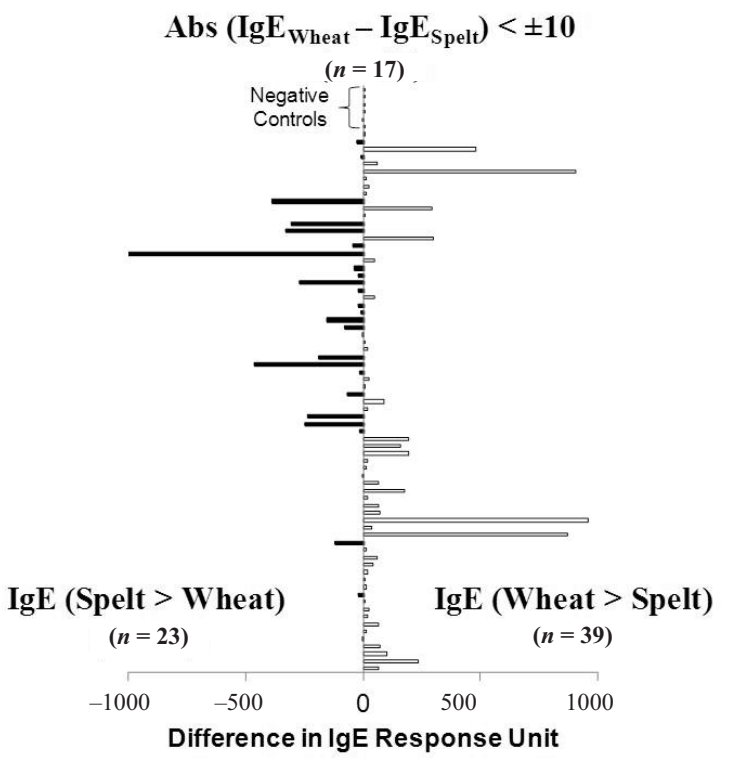

Figure 2. IgE response against wheat (f4) and spelt (f124) antigens

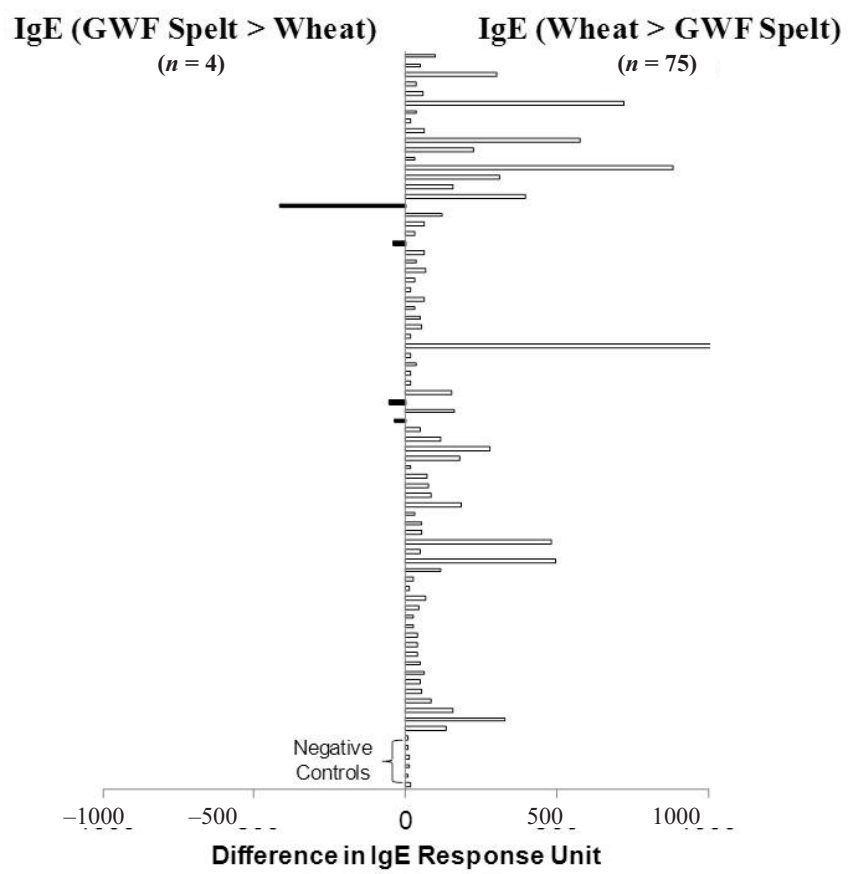

Figure 3. Differences in IgE response between wheat (f4) and GWF spelt in the selected group of individuals 
for wheat and $\mathrm{r}^{2}=0.88$ for spelt, respectively, allowing conversion of the data derived using the coupled streptavidin antigens to those using commercial antigens.

Using these relationships, the streptavidin coupled antigen data (GWF spelt) has been normalized to compare with the commercial Phadia wheat (f4) antigens (clinical benchmark). The IgE response against wheat (f4) was found to be significantly higher $(95 \%$ of the sera; $n=75$ ) than GWF spelt, and only 41 of these individuals (55\%) have IgE $>60 \mathrm{RU}$ against GWF spelt (Fig. 3). Four individuals showed higher IgE response against the GWF spelt than wheat but they are at a much lower intensity as compared to the Phadia antigens. This suggests GWF spelt elicits a significantly lower immune-response compared with the Phadia commercial spelt antigen (Fig. 2), where only $57 \%$ of sera had IgE $>60$ RU against GWF spelt as compared to $82 \%$ against the Phadia spelt antigen.

\section{Discussion}

Results shown in Table 2 indicate that in Australia the prevalence of wheat allergy in a randomly selected population is $2.5 \%$ where both positive IgE immune response and symptoms against wheat were observed. These results are in full agreement with similar investigations on wheat where the prevalence of wheat IgE sensitization in European countries is 2.9\% (Zuidmeer et al. 2008; Siles and Hsieh 2013). Specific IgE levels higher than the cut off value $(0.10 \mathrm{kU} / \mathrm{L}$ or $60 \mathrm{RU})$ suggests sensitization but are not necessarily predict clinical symptoms. Such tests can confirm the diagnosis of an allergic disorder, supplementing a clinical history consistent with an allergic reaction.

We postulate that the remaining $12.8 \%(n=125)$ of individuals who showed raised IgE antibody levels without symptoms may have a latent wheat sensitivity with the potential of developing symptoms sooner or later. The large proportion (12.9\%) of the investigated population who have symptoms associated with consumption of wheat products but did not demonstrate raised IgE may suffer from other wheat related disorders (i.e. not IgE mediated) such as celiac disease, non-celiac reaction to gluten or reaction to fructans (FODMAPS) for those with irritable bowel syndrome.

In contrast to celiac disease, where the toxic epitopes occur only in the prolamins (mostly in the gliadins but also in the HMW and LMW glutenin subunits), the epitopes responsible for allergenicity can be found both in the wheat prolamins and soluble proteins (Juhász et al. 2012).

There has been anecdotic clinical evidence for a long time that a large proportion of non-celiac patients suffering wheat related health disorders can tolerate products made from certain spelt varieties. Recently the first research paper with robust experimental and statistical results also demonstrated this important observation (Armentia et al. 2012). In our study GWF spelt was found to show significantly less immune reactivity than wheat and other spelts. It was also found that the albumin-globulin protein composition of GWF spelt is significantly different from other wheat and wheat related species ( $\mathrm{Vu}$ 2014). One of these differences has been identified by comparing the structure of genes coding the allergenic expansin proteins in different wheat and spelt germplasms. The expansin from GWF spelt has an insertion of three amino acids in the primary sequence and subsequently 
altering the conformation of the entire protein (Breen et al. 2010). This alteration in the soluble protein composition could be one of the reasons for the significantly lower immune reactivity of GWF spelt. A PCR based procedure, based on the above mutation in the expansin gene have been developed (Suter and Békés 2012) for screening of any contamination in grain or flour by other cereal with the wild type expansin protein during possible use for quality assurance purposes.

While these findings do provide some evidence to support the health benefits of this spelt line, only a clinical trial comparing the allergic symptoms and IgE levels caused by the consumption of wheat and GWF spelt products, involving both those that eat predominantly wheat and those who have replaced spelt for wheat in their diet, can answer the question as to whether our findings are associated with the apparent lower allergenicity of spelt for those with wheat allergy.

\section{Acknowledgements}

This project was funded by George Weston Foods Limited, NSW, Australia. We would like to thank Barwon Health and all the Geelong Osteoporosis Study patients, Victoria, Australia and Plant Breeding Institute, Cobbitty, NSW, Australia for their assistance and support.

\section{References}

Akagawa, M., Handoyo, T., Ishii, T., Kumazawa, S., Morita, N., Suyamam, K. 2007. Proteomic analysis of wheat flour allergens. J. Agric. Food Chem. 55:6863-6870.

Amano, M., Ogawa, H., Kojima, K., Kamidaira, T., Suetsugu, S., Yoshihama, M., Satoh, T., Samejima, T., Matsumoto, I. 1998. Identification of the major allergens in wheat flour responsible for baker's asthma. Biochem. J. 330:1229-1234.

Anderson, R.P., Degano, P., Godkin, A.J., Jewell, D.P., Hill, A.V.S. 2000. In vivo antigen challenge in celiac disease identifies a single transglutaminase-modified peptide as the dominant A gliadin T-cell epitope. Nature (Med) 6:337-342.

Anderson, R.P., Wieser, H. 2006. Medical applications of gluten-composition knowledge. In: Wrigley, C.W., Békés, F., Bushuk, W. (eds), Gliadin and Glutenin. The Unique Balance of Wheat Quality. AACCI Press, St. Paul, MN, USA, pp. 387-409.

Armentia, A., Martin-Santos, J.M., Blanco, M. 1990. Exercise induced anaphylaxis reaction to grain flours. Ann. Allergy 65:149-151.

Armentia, A., Martín, S., Diaz-Perales, A., Palacín, A., Tordesillas, L., Herrero, M., Martín-Armentia, M. 2012. A possible hypoallergenic cereal in wheat food allergy and baker's asthma. Am. J. Plant Sci. 3:1779-1781.

Braly, J., Hogganm, R. 2002. Dangerous Grains. Why Gluten Cereal Grains May Be Hazardous to your Health. Penguin Group, New York, NY, USA.

Breen, M., Li, D., Dunn, D.S., Békés, F., Kong, X., Zhang, J., Jia, J., Wicker, T., Mago, R. Ma, W., Bellgard, M., Appels, R. 2010. Wheat beta-expansion (EXPB11) genes: Identification of the expressed gene on chromosome 3BS carrying a pollen allergen domain. BMC Plant Biology 10:99.

Catassi, C., Fasano, A. 2008. Celiac disease. In: Arendt, E.K., Dal Bello, F. (eds), Gluten-free Cereal Products and Beverages. Academic Press, San Diego, CA, USA, pp. 1-28.

Corazza, G.R., Gasbarrini, G. 1995. Coeliac disease in adults. Baillières Clin. Gastroenterol. 9:329-350.

Davis, W. 2011. Wheat belly: Loose the Wheat and Find your Path back to Health. Rodale Books Inc., New York, USA. 
Erwin, E.A., Ronmark, E., Satinover, S.M., Perzanowski, M.S., Crane, J. 2005. Quantitative measurement of IgE antibodies to purified allergens using streptavidin linked to a high capacity solid phase. J. Allergy Cli. Immunol. 115:1029-1035.

Ford, R. 2008. The Gluten Syndrome. Is Wheat Causing you Harm? RRS Global LT, Christchurch, New Zealand.

Greco, L., Mäki, M., Di Donato, F., Visakorpi, J.K. 1992. Epidemiology of coeliac disease in Europe and the Mediterranean Area. A summary report on the multicentre study by the European Society of Paediatric Gastroenterology and Nutrition. In: Auricchio, S., Visakorpi, J.K. (eds), Common Food Intolerances 1: Epidemiology of Coeliac Disease. Dyn. Nutr. Res. Basel. Karger. Basel, Switzerland, pp. 25-44.

Green, P.H.R., Cellier, M.D.B. 2007. Celiac disease. New England J. Med. 357:1731-1743.

Hischenhuber, C., Crevel, R., Jarry, B., Mäki, M., Moneret Vautrin, D.A., Romano, A., Troncone, R., Ward, R. 2006. Review article: safe amounts of gluten for patients with wheat allergy or coeliac disease. Aliment. Pharmacol. Therapy J. 23:559-575.

Islam, S., Ma, W., Yan, G., Békés, F., Appels, R. 2011. Modifying processing and health attributes of wheat bread through changes in composition, genetics and breeding. In: Cauvain, S.P. (ed.), Bread Making. Improving Quality. $2^{\text {nd }}$ Edition. Woodhead Publishing Ltd. Cambridge, UK, pp. 259-296.

Johansson, G.S.O. 2004. ImmunoCAP specific immunoglobulin E test: Tool for research and allergy diagnosis. Expert. Rev. Mol. Diag. 4:89-95.

Juhász, A., Gell, Gy., Békés, F., Balázs, E. 2012. The epitopes in wheat proteins for defining toxic units relevant to human health. Funct. Integr. Genomics 12:585-598.

Laurière, M., Pecquet, C., Bouchez-Mahiout, I., Snegaroff, J., Bayrou, O., Raison-Peyron, N., Vigan, M. 2006. Hydrolyzed wheat proteins present in cosmetics can induce immediate hypersensitivities. Contact Dermatitis 54:283-289.

Mills, E.N.C., Jenkins, J.A., Alcocer, M.J.C., Shewry, P.R. 2004. Structural, biological, and evolutionary relationships of plant food allergens sensitizing via the gastrointestinal tract. Crit. Rev. Food Sci. Nutr. 44:379-407.

Ortolani, C., Pastorello, E.A. 2006. Food allergies and food intolerances. Best Practice and Res. Clin. Gastro. 20:467-483.

Pasco, J.A., Nicholson, G.C., Kotowicz, M.A. 2012. Cohort Profile: Geelong Osteoporosis Study. Int. J. Epidemiol. 41:1565-1575.

Rona, R.J., Keil, T., Summers, C., Gislason, D., Zuidmeer, L., Sodergren, E., Sigurdardottir, S.T Lindner, T. Goldhahn, K., Dahlstrom, J., McBride, D., Madsen, C. 2007. The prevalence of food allergy: A meta-analysis. J. Allergy Clin. Immunol. 120: 638-646.

Sapone, A., Bai, J.C., Ciacci, C., Dolinsek, J., Green, P.H.R., Hadjivassiliou, M., Kaukinen, K., Rostami, K., Sanders, D.S., Schumann, M., Ullrich, R., Villaltam D., Voltam U., Catassi, C., Fasano, A. 2012. Spectrum of gluten-related disorders: consensus on new nomenclature and classification. BMC Medicine 10:13.

Scholz, E., Ganzler, K., Gergely, S., Salgó, A. 2000. Separation of the unique proteins of wheat protein fractions by capillary electrophoresis. Chromatographia 51:S130-S134.

Siles, R.I., Hsieh, F.H. 2013. Allergy blood testing: A practical guide for clinicians. Cleveland Clinic J. Med. 78:585-592.

Sollid, L.M., Qiao, S.W., Andersonm, R.P., Gianfrani, C., Koning, F. 2012. Nomenclature and listing of celiac disease relevant gluten T-cell epitopes restricted by HLA-DQ molecules. Immunogenetics 64:455-460.

Suter, D., Békés, F. 2012. Wheat immunoreactivity. Australian Patent http://v3 .espacenet.com/publicationDetails/ biblio?CC=HU\&NR=AU2011000468

$\mathrm{Vu}$, N.T. 2014. Comparative analysis of the soluble wheat proteins and human health. PhD Thesis. Sydney University. Sydney, Australia.

Wangen, S. 2009. Healthier without Wheat: A New Understanding of Wheat Allergies, Celiac Disease and Non-celiac Gluten Intolerance. Innate Health Publ. Seattle, WA, USA.

Zuidmeer, L., Goldhahn, K., Rona, R.J., Gislason, D., Madsen, C., Summers, C., Sodergren, E., Dahlstrom, J., Lindner, T., Sigurdardottir, S.T., McBride, D., Keil, T. 2008. The prevalence of plant food allergies: A systematic review. J. Allergy Clin. Immunol. 121:1210-1218. 